\title{
The Evolution of Relative Brain Size in Marsupials Is Energetically Constrained but Not Driven by Behavioral Complexity
}

\author{
Vera Weisbecker $^{\mathrm{a}}$ Simon Blomberg ${ }^{\mathrm{a}}$ Anne W. Goldizen ${ }^{\mathrm{a}}$ Meredeth Brown ${ }^{\mathrm{b}}$ \\ Diana Fisher ${ }^{\mathrm{a}}$ \\ ${ }^{a}$ School of Biological Sciences, University of Queensland, St. Lucia, Qld., and b Department of Environment, \\ Water and Natural Resources, Adelaide, S.A., Australia
}

\section{Key Words}

Brain size · Marsupials · Maternal investment · Seasonality · Life history $\cdot$ Constraint

\begin{abstract}
Evolutionary increases in mammalian brain size relative to body size are energetically costly but are also thought to confer selective advantages by permitting the evolution of cognitively complex behaviors. However, many suggested associations between brain size and specific behaviors - particularly related to social complexity - are possibly confounded by the reproductive diversity of placental mammals, whose brain size evolution is the most frequently studied. Based on a phylogenetic generalized least squares analysis of a data set on the reproductively homogenous clade of marsupials, we provide the first quantitative comparison of two hypotheses based on energetic constraints (maternal investment and seasonality) with two hypotheses that posit behavioral selection on relative brain size (social complexity and environmental interactions). We show that the two behavioral hypotheses have far less support than the constraint hypotheses. The only unambiguous associates of brain size are the constraint variables of litter size and seasonality. We also found no association between brain size and specific behavioral complexity categories within kanga-
\end{abstract}

roos, dasyurids, and possums. The largest-brained marsupials after phylogenetic correction are from low-seasonality New Guinea, supporting the notion that low seasonality represents greater nutrition safety for brain maintenance. Alternatively, low seasonality might improve the maternal support of offspring brain growth. The lack of behavioral brain size associates, found here and elsewhere, supports the general 'cognitive buffer hypothesis' as the best explanatory framework of mammalian brain size evolution. However, it is possible that brain size alone simply does not provide sufficient resolution on the question of how brain morphology and cognitive capacities coevolve.

(c) 2015 S. Karger AG, Basel

\section{Introduction}

One of the most impressive mammalian traits is an extremely large brain relative to body size, which reflects the superior cognitive abilities of mammals compared to most other vertebrates. It is presumed that some aspect of improved cognition selects for the evolution of large brains relative to body size (here referred to as large brains') in mammals [Healy and Rowe, 2007; Dunbar, 2009a; van Woerden et al., 2012]. Selection-focused research into cognitive correlates of brain size therefore

\section{KARGER 125\%}

(c) 2015 S. Karger AG, Basel

0006-8977/15/0852-0125\$39.50/0

E-Mail karger@karger.com

www.karger.com/bbe
Vera Weisbecker

School of Biological Sciences, University of Queensland

8 Goddard Building

St. Lucia, QLD 4069 (Australia)

E-Mail v.weisbecker@uq.edu.au 
asks which behaviors are so cognitively complex that they require a larger brain [Dunbar, 1998; Weisbecker and Goswami, 2011]. A frustrating variety of selection factors [Healy and Rowe, 2007] have been proposed, which can be classified into two types [Dunbar, 1998]. The first, very popular, type is based on the 'social brain hypothesis' (SBH) [Dunbar, 1998]. This suggests that complex social bonds, particularly pair bonding, select for larger brain sizes [Marino, 2004; Shultz and Dunbar, 2006, 2010b; Walker et al., 2006; Dunbar and Shultz, 2007a]. The second type, whose constituent parameters could be called 'environmental interaction traits', includes interactions with the environment such as locomotor modes or circadian rhythms [e.g. Eisenberg and Wilson, 1981]. However, the practice of attaching specific behaviors to brain size evolution has been criticized. In particular, a third hypothesis not tied to specific behaviors - the 'cognitive buffer hypothesis' - simply states that large brains are advantageous because they allow for behavioral flexibility in novel or complex environments, for example during species invasions [Reader and Laland, 2002; Sol et al., 2007; Sol, 2009; Lefebvre et al., 2013].

The degree to which selection for large brains can act is limited by the considerable cost of large brains. Contrary to the relative inconclusiveness of selection-based research on mammals [Healy and Rowe, 2007], a large body of evidence shows that brain size is limited by maternal investment (the ability of females to provide sufficient nutrition for offspring brain growth) [Martin, 1981; Jones and MacLarnon, 2004; Martin et al., 2005; Finarelli, 2009a; Isler and Van Schaik, 2009; Shultz and Dunbar, 2010b; Weisbecker and Goswami, 2010, 2011; Barton and Capellini, 2011]. In addition, recent work on primates suggests that seasonality represents another energetic constraint on brain size [van Woerden et al., 2010, 2012] possibly because the brain depends on reliable nutrition.

Constraint-focused and selection-focused research on brain size are traditionally conducted separately, an approach that has sometimes been explicitly advocated [Dunbar and Shultz, 2007b; Dunbar, 2009b]. However, this separation is problematic because of the well-known connections between hypothesized behavioral selectors and constraining traits on brain size [Shultz and Dunbar, 2010b; van Woerden et al., 2010, 2012; Weisbecker and Goswami, 2011]. Social traits are particularly susceptible to such confounding factors because they often coevolve with particular life histories and developmental regimes [Temrin and Tullberg, 1995; Geffen et al., 1996; Bhumstein and Armitage, 1997; Hatchwell and Komdeur, 2000; Olson et al., 2008; González-Lagos et al., 2010; Shultz and
Dunbar, 2010b]. For example, pair bonding requires complex interactions and is proposed to be a key selector for larger brains [Dunbar and Shultz, 2007b], but it has also been argued to improve offspring provisioning by allowing females to invest more energy into their offspring's brain development [Isler and Van Schaik, 2009, 2012]. This issue is particularly relevant because of the near-exclusive research focus on placental mammals [exceptions are Eisenberg and Wilson, 1981; Legendre et al., 1994; Iwaniuk et al., 2000]. Placentals are interesting because they contain several extremely large-brained clades, such as primates (including humans), canid carnivores, and cetaceans. However, placentals vary greatly in life history and reproduction [Capellini et al., 2010; Barton and Capellini, 2011; Weisbecker and Goswami, 2011], which increases the risk that behavioral associates of placental brain size are confounded with life-history factors that exert maternal investment constraints.

Marsupial mammals are much more homogenous in their life history than placentals, thus presenting an opportunity to test hypotheses of mammalian brain size evolution in a framework that is less confounded by reproductive traits. For at least 60 million years [when the ancestors of modern-day marsupials diverged; Horovitz et al., 2009], marsupials have been born after an extremely short gestation (12-30 days) requiring little maternal energy [Tyndale-Biscoe, 2005]. Marsupial neonates are extremely altricial. Milk composition and lactation duration are more homogenous across marsupials than they are across placentals [Green and Merchant, 1988; Tyndale-Biscoe, 2005]. Marsupials display nearly all ecotypes and social behaviors considered relevant by selectionbased studies of brain size evolution (including pair bonding and allomaternal care, considered key constraining [Isler and Van Schaik, 2012] as well as selecting [Dunbar, 2009a] traits on brain size). In addition, marsupials allow the evaluation of a constraint of seasonality on brain size [van Woerden et al., 2010, 2012] because they are distributed from seasonal temperate to aseasonal equatorial biogeographical zones. In particular, representatives of all orders are also found in New Guinea (NG), which experiences little environmental seasonality [Feng et al., 2013], no seasonally predictable fluctuation in insect activity, and continuous rather than seasonal breeding of dasyurids, unlike most of Australia [Fisher et al., 2013]. This allows for testing of the hypothesis that seasonality associates with increased brain sizes, presumably due to a more consistent availability of food which allows the nutritional requirements of large brains to be met [van Woerden et al., 2010, 2012]. 
Table 1. Description of the traits used in the pgls models

\begin{tabular}{|c|c|c|c|}
\hline Trait & Units/categories & $\begin{array}{l}\text { Reasons proposed for the impact on } \\
\text { brain size evolution }\end{array}$ & References \\
\hline $\begin{array}{l}\text { Population } \\
\text { density }\end{array}$ & Individuals per hectare & $\begin{array}{l}\text { A dense population increases } \\
\text { cognitively intense social interactions }\end{array}$ & $\begin{array}{l}\text { Walker et al., 2006; Bailey and Geary, } \\
2009\end{array}$ \\
\hline Group living & $\begin{array}{l}\text { Solitary (1), living in a group } \\
(2)\end{array}$ & $\begin{array}{l}\text { Group living requires greater } \\
\text { recognition and interaction skills }\end{array}$ & $\begin{array}{l}\text { Shultz and Dunbar, 2006; Walker et al., } \\
\text { 2006; Dunbar and Shultz, 2007a }\end{array}$ \\
\hline Mating system & $\begin{array}{l}\text { Promiscuous (1), polygamous/ } \\
\text { monogamous/complex mating } \\
\text { systems (2) }\end{array}$ & $\begin{array}{l}\text { A greater mating bond complexity } \\
\text { requires more cognitively complex } \\
\text { social interaction }\end{array}$ & $\begin{array}{l}\text { Pitnick et al., 2006; Schillaci, 2006; } \\
\text { Shultz and Dunbar, } 2006\end{array}$ \\
\hline Home range & Hectares & $\begin{array}{l}\text { The spatial complexity of an } \\
\text { increased home range requires } \\
\text { improved cognition }\end{array}$ & $\begin{array}{l}\text { Clutton-Brock and Harvey, 1980; } \\
\text { Walker et al., 2006; Dunbar and Shultz, } \\
\text { 2007a }\end{array}$ \\
\hline Arboreality & $\begin{array}{l}1=\text { Arboreal or scansorial; } 2= \\
\text { terrestrial }\end{array}$ & $\begin{array}{l}\text { A complex arboreal environment is } \\
\text { cognitively demanding }\end{array}$ & $\begin{array}{l}\text { Eisenberg and Wilson, 1981; Mace et } \\
\text { al., 1981; Meier, } 1983\end{array}$ \\
\hline Diurnality & $\begin{array}{l}0=\text { Strictly nocturnal; } 1=\text { not } \\
\text { strictly nocturnal }\end{array}$ & $\begin{array}{l}\text { Nocturnal birds, primates, marsupials } \\
\text { are considered larger-brained }\end{array}$ & $\begin{array}{l}\text { Clutton-Brock and Harvey, 1980; } \\
\text { Eisenberg and Wilson, 1981; Mace et } \\
\text { al., 1981; Garamszegi et al., } 2002\end{array}$ \\
\hline Shelter safety & $\begin{array}{l}1=\text { Protected (burrow/ } \\
\text { constructed nest in a tree } \\
\text { hollow); } 2=\text { intermediate (tree } \\
\text { canopy/hollow log/under a } \\
\text { rock/nest on the ground or in } \\
\text { a soil crack); } 3=\text { open (under } \\
\text { shrubs/in grass/tree shade) }\end{array}$ & $\begin{array}{l}\text { Used as proxy for predation } \\
\text { particularly on juveniles [Fisher et al., } \\
\text { 2001]; predation pressure is } \\
\text { considered a selection factor for } \\
\text { larger brains }\end{array}$ & $\begin{array}{l}\text { Palombo et al., 2008; Dunbar, 2009b; } \\
\text { Kondoh, } 2010\end{array}$ \\
\hline Weaning age & Age at weaning & Maternal investment constraint & $\begin{array}{l}\text { Martin, 1981; Weisbecker, 2010; Isler } \\
\text { and Van Schaik, } 2012\end{array}$ \\
\hline
\end{tabular}

This study exploits the suitability of marsupials for studies of brain size evolution to jointly evaluate four hypotheses: the constraint-based 'maternal investment hypothesis' and 'seasonality hypothesis' and the selectionbased SBH and 'environmental interaction hypothesis'. Using phylogenetically corrected general least squares modeling and detailed within-clade analyses, we search for significant associations of the model variables with brain size and evaluate the relative explanatory power of the models.

Costs and Not Behavior Determine

Marsupial Brain Size

\section{Materials and Methods}

\section{Data Collection}

Data on marsupial endocranial volumes (proxies for brain size) and body mass were taken from Ashwell [2008] and Weisbecker et al. [2013], respectively. Based on a literature review, a set of potential brain size correlates representing the maternal investment, seasonality, social brain, and environmental interaction hypotheses were chosen (table 1) to form part of our data set (online suppl. material 1; see www.karger.com/doi/10.1159/000377666 for all online suppl. material). Note that basal metabolic rate, which is often included in constraint-based explanatory frameworks of mamma- 
lian brain evolution, is unlikely to associate with marsupial brain size [Weisbecker and Goswami, 2010, 2011, 2014] and was therefore excluded from the analysis. Data on maternal investment, social behaviors, and environmental interaction traits were mostly from Fisher et al. [2001, 2014]. Additional references for data on South American and NG marsupials and macropodoid (kangaroos, wallabies, and rat kangaroos) group complexity are listed in online supplementary material 2. Latitudinal data for Australian and NG species are from Fisher et al. [2014], with the addition of latitudinal estimates for some NG species based on averages of the maximum and minimum latitude [International Union for Conservation of Nature, 2014]. To avoid atomization and for sufficient sample sizes in each variable bin, broad categories were employed for the modeling analyses. For finer-grained assessment specifically of the $\mathrm{SBH}$, relative brain sizes were separately investigated in the following categories of group complexity: (1) macropodoids (kangaroos; $n=25$ ), with (a) solitary, (b) fission-fusion groups, or (c) polygynous social systems; (2) dasyurids (marsupial predators; $n=43$ ), with (a) communal (genus Antechinus, which nests in family groups) or (b) solitary social systems, and (3) petauroids (ringtail possums and gliders; $\mathrm{n}=25$ ), with (a) no paternal/family care, (b) extended family care, or (c) paternal care. If varying behaviors were reported for different populations of a species, we scored the one considered more complex (e.g. monogamy over polygyny in brush-tailed possums [Brown et al., 2007; Martin and Martin, 2007]).

\section{Model Selection and Fitting}

Four models, all with logarithm-transformed brain volume as the dependent variable, were compiled from the data and compared. The predictor variables of the SBH model $(n=63)$ included group size, parental care, mating system, and population density. The 'environmental interaction model' $(\mathrm{n}=97)$ included home range size, diurnality, shelter safety, diet, and locomotor type. The 'maternal investment constraint model' $(\mathrm{n}=92)$ included litter sizes and weaning age. The 'seasonality constraint model' $(n=178)$ compared marsupials from NG to marsupials from Australia. The assembly of the four models according to established hypotheses allowed us to distribute the variables into biologically meaningful sets that have previously been associated with brain size, while allowing a good balance between the sample sizes and the variables tested. However, the models are not mutually exclusive as constituent variables of several models could conceivably associate with brain size.

Body size heavily influences many biological variables [Martin et al., 2005], often in a nonlinear and complex way [Sibly and Brown, 2007; Anderson-Teixeira et al., 2009], which might result in different associations between brain size and the predictor variables at different body sizes. To address this, aside from including body size as a covariate in all models, we initially computed ANOVA tables of models in which an interaction of each variable with log body size was included. Due to the resulting strong collinearity in the models, determined by assessment of variance inflation factors as computed in the car package [Fox and Weisberg, 2011] in R, we first computed type II SSQ ANOVA tables to assess whether any of the interaction terms with body mass were significant. Nonsignificant interaction terms were dropped from the final model ANCOVAs, resulting in substantially lower variance inflation factors.

Models were fit using phylogenetic generalized least squares (pgls), computed by the nlme [Pinheiro et al., 2014] and ape [Paradis et al., 2004] packages in R 2.15.2 [R Core Team, 2014]. This avoids problems of phylogenetic nonindependence [Felsenstein, 1985] by incorporating an estimate of the sample's phylogenetic correlation structure and branch lengths. We collated a compound phylogeny based on the recent literature (online suppl. material 2, 3 ) and computed several branch length transformations (ultrametricized according to Grafen [1989], Nee [Purvis, 1995], and Pagel [1992] in Mesquite version 2.75 [Maddison and Maddison, 2011]) and evolutionary models (Brownian motion, Pagel [1999], and Grafen [1989]). We determined the best combination of branch length and evolutionary model for each of our models by determining the relative likelihoods of each combination based on Akaike scores [Burnham and Anderson, 2002; Grigione et al., 2002].

ANOVA tables of all models were computed using type II sums of squares (type II SSQ) and the most likely phylogenetic settings as described above. The use of type II SSQ is a conservative approach that calculates associations of each variable with the dependent variable after adding all other variables to the model. This also avoids the issue of needing to specify a variable input order, which in our case would have been arbitrary and artificial.

We also fit three of the models (social brain, environmental interaction, and maternal investment constraints) based on a smaller joint data set ( $\mathrm{n}=59$; it is a prerequisite of Akaike comparisons that the models are run with the same data and the same correlation structure). This allowed us to use Akaike weight score comparisons to determine which of the models was most likely. To this comparison, we also added a model with body size as the only predictor variable, to assess whether body size is the only likely predictor of brain size. The scant information available on the life history and behaviors of NG marsupials would have diminished the number of species in a joint data set, so that the seasonality constraint model was not compared to the other three models. Mammals on islands such as NG have been suggested to both increase and decrease body size faster than brain size [Palombo et al., 2008; Weston and Lister, 2009]. To determine whether our results might be influenced by such an island effect, a pgls model comparing body size in NG marsupials and all other species was also computed.

\section{pgls Residual and Within-Clade Analyses}

From the within-clade data, we used ANOVA tables of pgls models as described above to assess whether behavioral categories within macropodoids, dasyurids, and petauroids were associated with brain size. A pgls ANOVA table to assess whether the overall more social radiation of petauroid possums (ringtail possums, gliders, and allies) was larger-brained than all other marsupials was also computed.

\section{Results}

\section{Model Fitting}

The only variables that unambiguously associated with brain size (aside from body size) were litter size, NG origins, and, with weak significance, latitude. For a visual representation of the relative brain sizes of species of $\mathrm{NG}$ origins, as well as mating complexity (one of the most important variables of the SBH), see figure 1 . 
Table 2. ANOVA tables of the pgls models, including model formulae and phylogeny settings

\begin{tabular}{|c|c|c|c|c|}
\hline & $\mathrm{F}$ & $\mathrm{p}$ & AIC & $\lambda$ or $\rho$ \\
\hline Maternal investment model ${ }^{1}$ & & & 0.57 & 0.89 \\
\hline Body mass & 532.04 & 0.000 & & \\
\hline Litter size & 5.4 & 0.0223 & & \\
\hline Weaning age & 1.39 & 0.2408 & & \\
\hline Social brain model ${ }^{2}$ & & & 0.000 & 1 \\
\hline Body mass & 367.08 & 0.000 & & \\
\hline Group size & 8.34 & 0.0052 & & \\
\hline Parental care & 0.03 & 0.86 & & \\
\hline Mating system & 0.00 & 0.96 & & \\
\hline Population density & 5.76 & 0.02 & & \\
\hline Group size:body mass & 8.36 & 0.0052 & & \\
\hline Population density:body mass & 6.2 & 0.01 & & \\
\hline Environmental interaction model ${ }^{3}$ & & & 0.000 & 1 \\
\hline Body mass & 312.89 & 0.000 & & \\
\hline Diurnality & 2.03 & 0.16 & & \\
\hline Shelter safety & 0.68 & 0.52 & & \\
\hline Arboreality & 1.56 & 0.22 & & \\
\hline Diet & 0.83 & 0.49 & & \\
\hline Home range & 0.17 & 0.68 & & \\
\hline Body size only model ${ }^{4}$ & & & 0.43 & 0.29 \\
\hline Body mass & $1,163.02$ & 0.000 & & \\
\hline Geographical distribution model ${ }^{5}$ & & & Not compared & 0.84 \\
\hline Body mass & 977.27 & 0.000 & & \\
\hline NG origins & 10.36 & 0.0016 & & \\
\hline Latitude & 4.12 & 0.044 & & \\
\hline
\end{tabular}

Significant associations between brain size and variables are shown in bold. Intercepts of all models were highly significant at $\mathrm{p}=0.000$. AIC $=$ Akaike $\mathrm{W}$ score of a comparison of the first three models based on a joint data set $(n=59)$; $\lambda$ or $\rho=$ Pagel's lambda or Grafen's rho (measuring phylogenetic signal in the data set; Brownian motion is 1 for $\lambda$ or $\rho$ ).

${ }^{1} \log$ brain size litter size $+\log$ weaning age $+\log$ body mass, d.f. $=90$, assuming a Pagel-ultrametricized tree and Pagel's correlation structure.

${ }^{2} \log$ brain size $\sim$ group size $\cdot \log$ body mass + parental care + mating system + log population density $\cdot \log$ body mass $+\log$ body mass, d.f. $=56$, assuming a Pagel-ultrametricized tree and Brownian motion.

${ }^{3} \log$ brain size $\sim$ diurnality + shelter safety + arboreality + diet $+\log$ home range $+\log$ body mass, d.f. $=60$, assuming a Pagel-ultrametricized tree and Brownian motion.

${ }^{4} \log$ brain size $\log$ body mass, d.f. $=180$, assuming a Grafen-ultrametricized tree with Grafen's correlation structure.

${ }^{5} \log$ brain size $\sim$ NG origins + latitude $+\log$ body mass, d.f. $=178$, assuming a Nee-ultrametricized tree and Pagel's correlation structure.

In all models except the SBH model, interaction terms with body size were nonsignificant so that the final models were run without interactions (table 2). However, the final SBH model included significant interactions of population density and group size variables with body size, as well as significant associations of these two variables with brain size. The significance of the interaction terms was weak (near $\mathrm{p}=0.01$ ), the model was highly collinear, and the model's coefficients revealed interaction term parameter values an order of magnitude smaller than those of the main effects (online suppl. material 4). Nevertheless, we retained the interaction terms in the model because, although they are of a small magnitude, they are unlikely to be exactly zero (for the model without interactions and extended reports of model coefficients, see online suppl. material 4). 
Fig. 1. Log brain volume plotted against log body mass, with a pgls fit line, with NG species and species with nonpromiscuous mating systems highlighted.

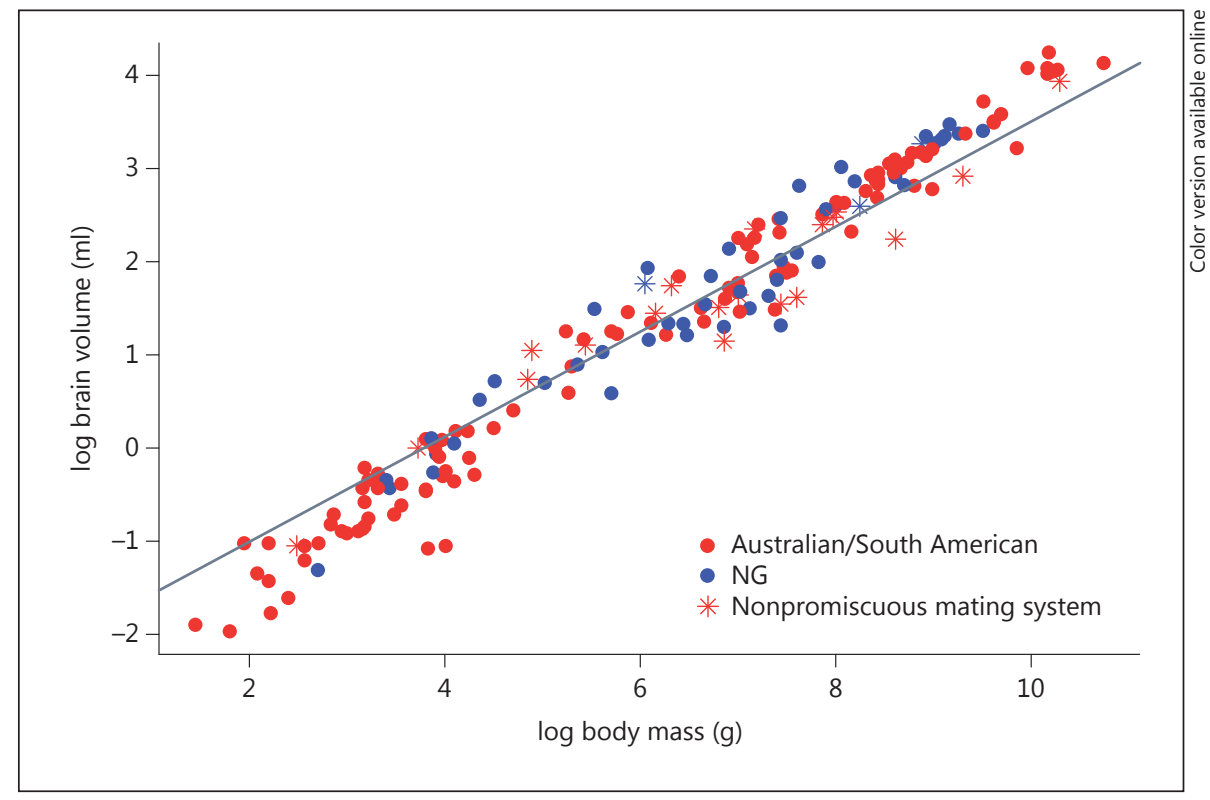

Table 3. ANOVA tables of pgls models for within-clade analysis

\begin{tabular}{lcll}
\hline & $\mathrm{F}$ & $\mathrm{p}$ & $\lambda$ or $\rho$ \\
\hline Macropodoids & & & 0.72 \\
Intercept & 7.6 & $\mathbf{0 . 0 1 2}$ & \\
Body mass & 87.8 & $\mathbf{0 . 0 0 0}$ & \\
Group complexity & 0.56 & 0.58 & \\
\hline Dasyurids & & & 0.87 \\
Intercept & & $\mathbf{0 . 0 0 0}$ & \\
Body mass & 70.59 & $\mathbf{0 . 0 0 0}$ & \\
Communal nesting & 174.65 & 0.98 & \\
\hline Within petauroids & & \\
Intercept & & & \\
Body mass & 48.49 & $\mathbf{0 . 0 1 2}$ & \\
Parental care type & 108.92 & $\mathbf{0 . 0 0 0}$ & \\
\hline Petauroids vs. other marsupials $^{4}$ & & \\
Intercept & 80.06 & $\mathbf{0 . 0 0 0}$ & \\
Body mass & $1,217.8$ & $\mathbf{0 . 0 0 0}$ & \\
Petaurid affinity & 1.74 & 0.189 & \\
\hline
\end{tabular}

\footnotetext{
${ }^{1} \log$ brain size $\sim$ group complexity $+\log$ body mass, $\mathrm{n}=25$, assuming a Grafen-ultrametricized tree and Pagel's correlation structure. ${ }^{2} \log$ brain size communal nesting $+\log$ body mass, $\mathrm{n}=$ 43, assuming a Grafen-ultrametricized tree and Pagel's correlation structure ${ }^{3} \log$ brain size $\sim$ parental care type + log body mass, $n=$ 25, assuming a Pagel-ultrametricized tree and Brownian motion. ${ }^{4} \log$ brain size $\sim$ petauroid clade affinity $+\log$ body mass, $n=180$, assuming a Grafen-ultrametricized tree and Grafen's correlation structure.

$p$-values indicating significance $(p \leq 0.05)$ are bold. $\lambda$ or $\rho=$ Pagel's lambda or Grafen's rho.
}

A possibly confounding impact of an island effect on body size, where a fast change in body size would result in either relatively smaller or larger brains, could be excluded as NG species did not have significantly different body sizes ( $\mathrm{p}=0.450$; Pagel's correlation structure, Neetransformed branch lengths).

Akaike weight comparisons (table 2) showed that the likelihood of the maternal investment model was far greater relative to that of the social complexity and environmental interaction models. The maternal investment constraint model was also more likely than the body mass only model.

None of the social behavior types within the separate models of dasyurids, macropodoids, within-petauroids and between petauroids versus marsupials were significantly associated with brain size (fig. 2; table 3). Notably, NG marsupials of all Australidelphian orders were well represented within the $5 \%$ of species with the relatively largest brains ( 6 out of a total of 9), as determined by the residuals from the regression shown in figure 1 (for largest- and smallest-brained species, see table 4). Of these, the only potentially social species was the petauroid Dactylonax palpator, a little-studied close relative of the striped possum Dactylopsila trivirgata, which can nest in pairs or groups that interact frequently [Handasyde and Martin, 1996; McKenna, 2005]. In a zoo colony, Dactylopsila showed no signs of pair bonding or paternal care [McKenna, 2005]. The remaining species within the top $5 \%$ bracket include the solitary omnivorous bilby, the 


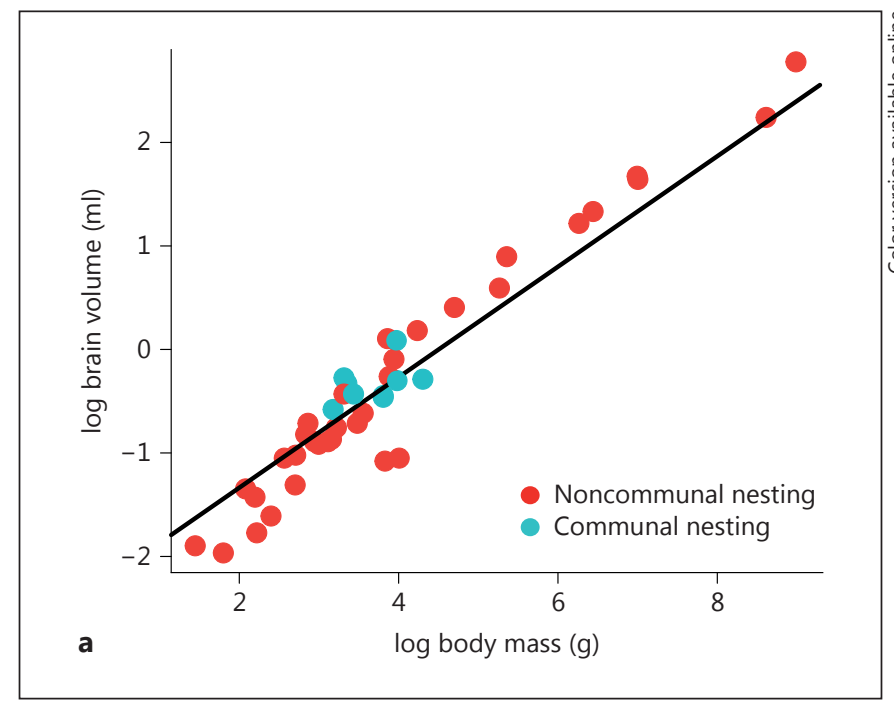

Fig. 2. Log brain volume plotted against log body mass, with a pgls fit line, in dasyurids (a), macropodoids (b), and petauroids (c) with two different types of social organization.

probably solitary carnivorous NG dasyurids Myoictis melas and Murexia longicauda, the solitary omnivorous NG spiny bandicoot Peroryctes raffrayana, the solitary folivorous NG tree kangaroo Dendrolagus dorianus, and the solitary NG folivorous phalanger Phalanger carmelitae. By contrast, two petauroid possum species with strong pair bonds - the rock-haunting possum Petropseudes dahli, which displays obligate pair bonding and paternal care [Runcie, 2000], and the lemuroid ringtail possum Hemibelideus lemuroides, which is organized in family groups [Winter and Atherton, 1984] - are among species with the lowest $10 \%$ of pgls residuals; even without phylogenetic corrections, these species are very smallbrained relative to similarly sized marsupials.

Costs and Not Behavior Determine Marsupial Brain Size
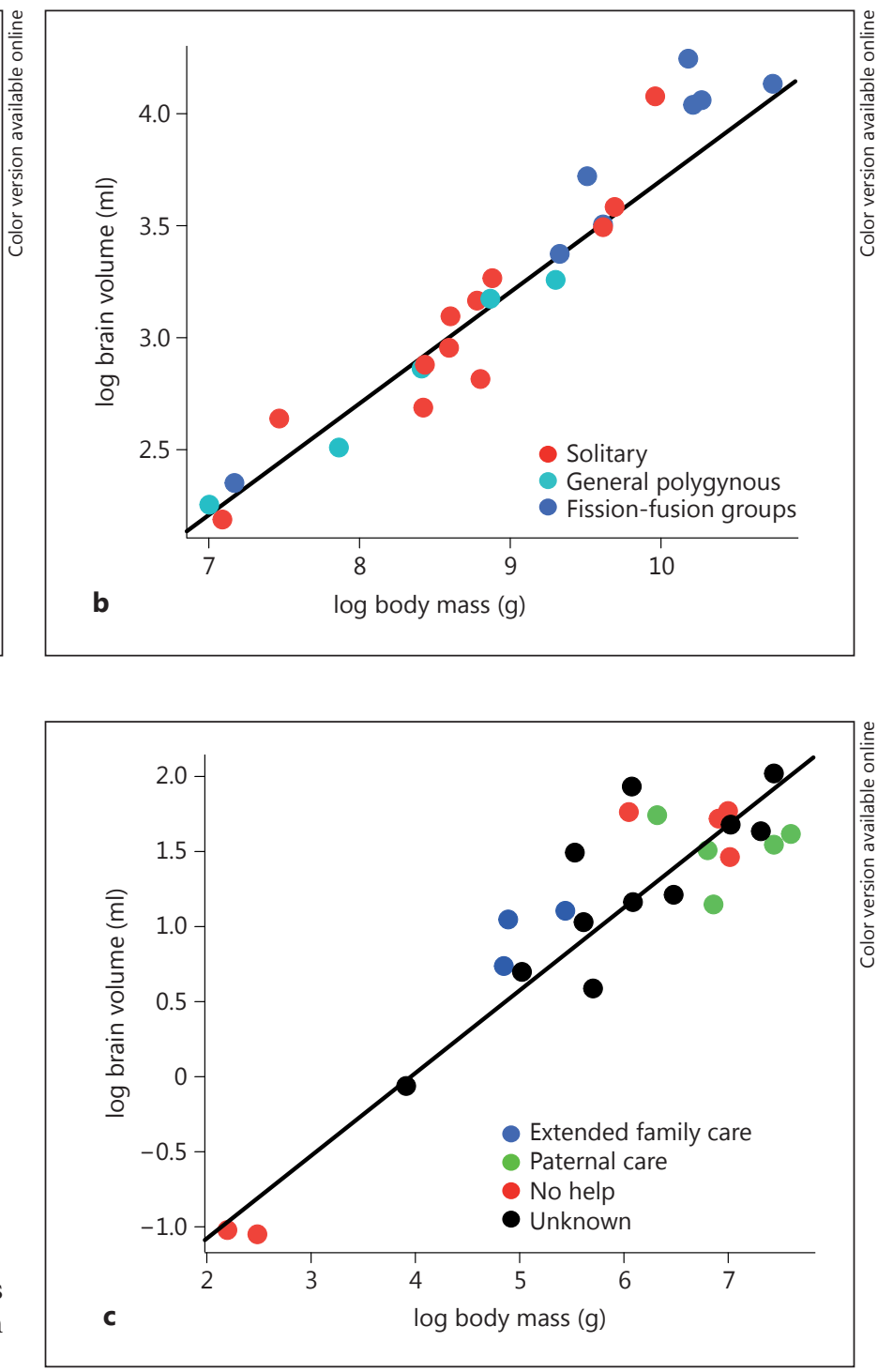

\section{Discussion}

Our study reveals solid support for the two hypotheses that posit an energetic constraint on mammalian brain size, while adding the subclass of Marsupialia to the considerable number of placental clades for which no connections between social complexity and relative brain size are apparent [Walker et al., 2006; Healy and Rowe, 2007; Finarelli, 2009b; Shultz and Dunbar, 2010b]. Specifically, the maternal investment constraint model has far more support than the environmental interaction and social brain models. In addition, the constraint-based variables of litter size and NG origins (as well as possibly latitudinal distribution, which was close to the significance cutoff) 
Table 4. Top and bottom $10 \%$ of residuals from a pgls fit of brain size versus body size in all marsupials $(\mathrm{n}=180$; assuming Pagel-ultrametricized trees and Grafen's correlation structure)

\begin{tabular}{llll}
\hline Bottom 10\% & & Top 10\% & \\
\hline Sminthopsis douglasi & -3.24186794 & Dendrolagus goodfellowi & $\mathbf{1 . 2 5 3 3 9 9}$ \\
Hemibelideus lemuroides & -2.51278287 & Sminthopsis griseoventer & 1.31274 \\
Marmosa robinsoni & -2.48021863 & Microperoryctes longicaudata & $\mathbf{1 . 3 3 9 2 3 6}$ \\
Planigale gilesi & -2.12058413 & Macropus giganteus & 1.381831 \\
Cercartetus concinnus & -2.00173976 & Antechinus stuartii & 1.46412 \\
Phalanger orientalis & $-\mathbf{1 . 9 8 4 4 9 3 5 3}$ & Dorcopsis atrata & $\mathbf{1 . 5 1 3 1 3 9}$ \\
Macropus greyi & -1.98237692 & Thylacinus cynocephalus & 1.531801 \\
Echymipera rufescens & -1.92536399 & Caluromys philander & 1.53887 \\
Sminthopsis virginiana & -1.92057437 & Dendrolagus lumholtzi & $\mathbf{1 . 5 4 3 5 0 3}$ \\
Phalanger lullulae & -1.80482822 & Antechinus swainsonii & 1.564659 \\
Cercartetus nanus & -1.63024674 & Phalanger carmelitae & $\mathbf{1 . 5 6 8 3 6 8}$ \\
Petropseudes dahli & -1.62178071 & Peroryctes raffrayana & $\mathbf{1 . 9 4 2 0 0 1}$ \\
Pseudantechinus roryi & -1.55530299 & Myoictis melas & $\mathbf{1 . 9 6 9 0 2 4}$ \\
Monodelphis brevicaudata & -1.38261595 & Dendrolagus dorianus & $\mathbf{2 . 0 9 3 8 4 4}$ \\
Dasyurus maculatus & -1.26887549 & Perameles bougainville & $\mathbf{2 . 1 8 4 2 0 1}$ \\
Pseudocheirus canescens & $-\mathbf{1 . 2 6 1 1 9 5 2 2}$ & Murexia longicaudata & $\mathbf{2 . 2 9 6 1 5}$ \\
Didelphis marsupialis & -1.1925408 & Dactylonax palpator & $\mathbf{2 . 3 6 8 3 7 2}$ \\
Antechinomys laniger & -1.16566976 & Macrotis leucura & 2.450916 \\
\hline
\end{tabular}

Dark grey covers $0-5 \%$, and light grey covers $5-10 \%$. NG species are bold, and social or potentially social species are bold and underlined.

are the only unambiguous associates of marsupial brain size. The significantly larger brains of NG marsupials in particular provide good support for the notion that low seasonality represents 'nutrition safety' for the brain [van Woerden et al., 2010, 2012]. It is possible that this effect is amplified by the better soils of NG, which might contribute to better food availability overall [Flannery, 1994; Ashwell, 2008]. However, this needs further research, since many NG ecosystems - particularly rainforest communities - are on fairly poor soil.

The significant associations between low-seasonality NG origins and litter size with marsupial brain size raise the intriguing possibility that the effects of these two variables on brain size are mechanistically linked. It is possible that the improved food availability in NG allows females to provide their offspring with more consistent or better nutrition, thus allowing their young to grow larger brains. In this context, it is worth noting that lactational investment may possibly play a role in the raising of largebrained offspring, despite the lack of an association of weaning age with brain size in our analyses. This is because such an association may be obscured by the strong phylogenetic signal from peramelids (bandicoots) and didelphids (opossums), which are extremely fast-weaning and small-brained [Weisbecker and Goswami, 2014].
However, at present the notion of a link between low seasonality and improved maternal investment cannot be distinguished from the current view that low seasonality facilitates the consistent nutrition of adult brains [van Woerden et al., 2010, 2012].

Our results show that selection for social complexity - such as pair bonding and group living - is not a pervasive influence on the evolution of large mammalian brains [Dunbar, 1998, 2009b; Shultz and Dunbar, 2006, 2010b; Dunbar and Shultz, 2007b]. This result is consistent with our suspicion that many of the social complexity/brain size associations found in placentals arise from a confounding influence of reproductive life history traits on social complexity patterns. We found no indication that more socially complex dasyurids, macropodoids, and petauroids are larger-brained than other members of their respective clades; indeed, the anecdotal evidence from single species shows that several marsupials with high degrees of social complexity are particularly smallbrained. The lack of an association between brain size and parental care is interesting because allomaternal care (where mothers are helped to raise their offspring) has been convincingly linked to larger brain sizes because it improves the ability of mothers to supply energy to their offspring. Canid carnivores in particular show this pat- 
tern [Isler and Van Schaik, 2012], but it clearly is not a factor in marsupial brain size evolution.

A caveat remains that significant interactions between population density and group size with body mass preclude a decision as to whether these two parameters influence brain size. As discussed above, however, significant interactions within the model were of small magnitude while a noninteraction model returned no association of population density or group size with brain size. The model performed extremely poorly relative to other models in the Akaike information criterion comparisons, suggesting that the variables contained in the model do not explain much of brain size variation regardless of the details of their association.

The lack of reliable behavioral correlates of increased brain size, found here and in other studies [Walker et al., 2006; Healy and Rowe, 2007; Finarelli, 2009b; Shultz and Dunbar, 2010b], is in stark relief to the clearly high costs of raising large-brained offspring [Dunbar, 2009b]. Why was this selection gradient so spectacularly overcome first by the ancestors of mammals [Rowe et al., 2011] and again in several mammalian radiations? It is possible that searching for specific behaviors that might have caused such selection is the wrong approach, as proponents of the cognitive buffer hypothesis suggest. Instead, largerbrained mammals and birds seem to be more successful when faced with challenges that require a general ability to deal with cognitive challenges [Sol, 2009; GonzálezLagos et al., 2010; van Woerden et al., 2012]. This is supported by the fact that extremely large-brained mammals, such as odontocetes and primates, exhibit high social complexity but also excel in many other areas of cognition (including learning, spatial orientation ability, and sensorimotor skills [González-Lagos et al., 2010; Kondoh, 2010]).

Another issue is highlighted by an increasing body of evidence that relative brain size per se contains too much noise to be an accurate predictor of mammalian cognition, as it does not reflect the brain infrastructure very well. Recent success in using brain components to understand the evolution of brain macromorphology [Sakai et al., 2011; Swanson et al., 2012; Gómez-Robles et al., 2014] and particular behaviors [de Winter and Oxnard, 2001], together with the realization that cell density and connectivity differ substantially among mammals [HerculanoHouzel et al., 2007, 2011; Sarko et al., 2009; Huang et al., 2014], also suggest that overall brain size may be too vague a predictor of cognitive ability. There is mounting evidence that relatively large brains often arise through selection for a smaller body size, rather than larger brain size [Fitzpatrick et al., 2012; Smaers et al., 2012; Swanson et al., 2012], so that in many cases no cognitive selectors of large brain size may exist.

In summary, our results suggest that marsupial brain size is not driven by selection for specific behaviors, as suggested by work on various placental clades. We suspect that much of the behavioral signal from placentals might arise from the confounding influence of their diverse reproduction. The only clear signal arising from our work and that of others is that marsupial brain size and mammalian brain size in general are constrained by nutritional requirements whose precise nature remains to be elucidated. Further understanding of this cost-benefit conundrum might be improved by linking work on brain macromorphology with the physiological and cellular properties of the evolving mammalian brain and consideration of the structure and physiology of brain tissue.

\section{Acknowledgements}

This research was funded by a Discovery Early Career Research Award (DE120102034), a Discovery Project grant (DP140102656) to V.W., a Future Fellowship (FT110100191) to D.F., and an Australian Research Fellowship (DP0773920) to D.F. Support from the Australian Mammal Society to V.W. is gratefully acknowledged. We thank N. Freeman for help with the collection of social complexity data, and A. Goswami and K. Aplin for advice. We thank two reviewers for insightful comments that improved the manuscript.

\section{References}

\footnotetext{
Anderson-Teixeira KJ, Savage VM, Allen AP, Gillooly JF (2009): Allometry and metabolic scaling in ecology. In: Encyclopedia of Life Sciences, Chichester, Wiley.

-Ashwell K (2008): Encephalisation of Australian and New Guinean marsupials. Brain Behav Evol 71:181-199.

Bailey D, Geary D (2009): Hominid brain evolu-
} tion. Hum Nat 20:67-79.
Costs and Not Behavior Determine

Marsupial Brain Size
Brain Behav Evol 2015;85:125-135 DOI: $10.1159 / 000377666$ 
Bhumstein DT, Armitage KB (1997): Life history consequences of social complexity - a comparative study of ground-dwelling sciurids. Behav Ecol 9:8-19.

Brown M, Carthew SM, Cooper SJB (2007): Monogamy in an Australian arboreal marsupial, the yellow-bellied glider (Petaurus australis). Aust J Zool 55:185-195.

Burnham KP, Anderson DR (2002): Model Selection and Multi-Model Inference. Springer New York.

-Capellini I, Venditti C, Barton RA (2010): Placentation and maternal investment in mammals. Am Nat 177:86-98.

Clutton-Brock TH, Harvey PH (1980): Primates, brains and ecology. J Zool 190:309-323.

de Winter W, Oxnard CE (2001): Evolutionary radiations and convergences in the structural organization of mammalian brains. Nature 409:710-714.

Dunbar RIM (1998): The social brain hypothesis. Evol Anthropol 9:178-190.

Dunbar RIM (2009a): The social brain hypothesis and its implications for social evolution. Ann Hum Biol 36:562-572.

Dunbar RIM (2009b): Darwin and the ghost of Phineas Gage: neuro-evolution and the social brain. Cortex 45:1119-1125.

Dunbar RIM, Shultz S (2007a): Understanding primate brain evolution. Philos Trans R Soc Lond B Biol Sci 362:649-658.

Dunbar RIM, Shultz S (2007b): Evolution in the social brain. Science 317:1344-1347.

-Eisenberg JF, Wilson DE (1981): Relative brain size and demographic strategies in didelphid marsupials. Am Nat 118:3-15.

Felsenstein J (1985): Phylogenies and the comparative method. Am Nat 125:1-15.

-Feng X, Porporato A, Rodriguez-Iturbe I (2013): Changes in rainfall seasonality in the tropics. Nature Clim Chang 3:811-815.

-Finarelli JA (2009a): Does encephalization correlate with life history or metabolic rate in Carnivora? Biol Lett 6:350-353.

Finarelli JA (2009b): Brain-size evolution and sociality in Carnivora. Proc Natl Acad Sci USA 106:9345-9349.

- Fisher DO, Dickman CR, Jones ME, Blomberg SP (2013): Sperm competition drives the evolution of suicidal reproduction in mammals. Proc Natl Acad Sci USA 110:17910-17914.

-Fisher DO, Johnson CN, Lawes MJ, Fritz SA, McCallum H, Blomberg SP, Van Der Wal J, Abbott B, Frank A, Legge S, Letnic M, Thomas CR, Fisher A, Gordon IJ, Kutt A (2014): The current decline of tropical marsupials in Australia: is history repeating? Glob Ecol Biogeogr 23:181-190.

- Fisher DO, Owens IPF, Johnson CN (2001): The ecological basis of life history variation in marsupials. Ecology 82:3531-3540.

-Fitzpatrick JL, Almbro M, Gonzalez-Voyer A, Hamada S, Pennington C, Scanlan J, Kolm N (2012): Sexual selection uncouples the evolution of brain and body size in pinnipeds. J Evol Biol 25:1321-1330.
Flannery TF (1994): The Future Eaters. Melbourne, Reed Books.

-Fox J, Weisberg S (2011): An R Companion to Applied Regression, ed 2. Thousand Oaks, Sage, Thousand Oaks CA.

Garamszegi LZ, Møller AP, Erritzøe J (2002): Coevolving avian eye size and brain size in relation to prey capture and nocturnality. Proc $\mathrm{R}$ Soc Lond B Biol Sci 269:961-967.

-Geffen E, Gompper ME, Gittleman JL, Luh H-K, Macdonald D, Wayne RK (1996): Size, life-history traits, and social organization in the Canidae: a reevaluation. Am Nat 147:140-160.

Gómez-Robles A, Hopkins WD, Sherwood CC (2014): Modular structure facilitates mosaic evolution of the brain in chimpanzees and humans. Nat Commun 5:4469.

González-Lagos C, Sol D, Reader SM (2010): Large-brained mammals live longer. J Evol Biol 23:1064-1074.

Grafen A (1989): The phylogenetic regression. Phil Trans R Soc B Biol Sci 326:119-156.

Green B, Merchant JC (1988): The composition of marsupial milk; in Tyndale-Biscoe $\mathrm{CH}$, Janssens PA (eds): The Developing Marsupial. Berlin, Springer, pp 41-54.

Grigione MM, Beier P, Hopkins RA, Neal D, Padley WD, Schonewald CM, Johnson ML (2002): Ecological and allometric determinants of home-range size for mountain lions (Puma concolor). Anim Conserv 5:317-324.

Handasyde K, Martin R (1996): Field observations on the common striped possum (Dactylopsila trivirgata) in North Queensland. Wildl Res 23:755-766.

-Hartwig W, Rosenberger AL, Norconk MA, Owl MY (2011): Relative brain size, gut size, and evolution in New World monkeys. Anat Rec 294:2207-2221.

-Hatchwell BJ, Komdeur J (2000): Ecological constraints, life history traits and the evolution of cooperative breeding. Anim Behav 59:10791086.

Healy SD, Rowe C (2007): A critique of comparative studies of brain size. Proc Biol Sci 274: 453-464.

Herculano-Houzel S, Collins CE, Wong P, Kaas JH (2007): Cellular scaling rules for primate brains. Proc Natl Acad Sci USA 104:35623567.

Herculano-Houzel S, Ribeiro P, Campos L, Valotta da Silva A, Torres LB, Catania KC, Kaas JH (2011): Updated neuronal scaling rules for the brains of Glires (rodents/lagomorphs). Brain Behav Evol 78:302-314.

Horovitz I, Martin T, Bloch J, Ladevèze S, Kurz C, Sánchez-Villagra MR (2009): Cranial anatomy of the earliest marsupials and the origin of opossums. PLoS One 4:e8278.

-Huang C, Gammon SJ, Dieterle M, Huang RH, Likins L, Ricklefs RE (2014): Dramatic increases in number of cerebellar granule-cellPurkinje-cell synapses across several mammals. Mamm Biol 79:163-169.

International Union for Conservation of Nature (2014): The IUCN Red List of Threatened Species, version 2014.2.
Isler K, Van Schaik CP (2009): The expensive brain: a framework for explaining evolutionary changes in brain size. J Hum Evol 57:392400.

Isler K, Van Schaik CP (2012): Allomaternal care, life history and brain size evolution in mammals. J Hum Evol 63:52-63.

Iwaniuk AN, Nelson JE, Whishaw IQ (2000): The relationships between brain regions and forelimb dexterity in marsupials (Marsupialia): a comparative test of the principle of proper mass. Aust J Zool 48:99-110.

Jones KE, MacLarnon A (2004): Affording larger brains: testing hypotheses of mammalian brain evolution in bats. Am Nat 164:E20-E31

Kondoh M (2010): Linking learning adaptation to trophic interactions: a brain size-based approach. Funct Ecol 24:35-43.

Lefebvre L, Reader SM, Sol D (2013): Innovating innovation rate and its relationship with brains, ecology and general intelligence. Brain Behav Evol 81:143-145.

Legendre P, Lapointe FJ, Casorain P (1994): Modeling brain evolution from behavior: a permutational regression approach. Evolution 48: 1487-1499.

Mace GM, Harvey PH, Clutton-Brock TH (1981): Brain size and ecology in small mammals. J Zool 193:333-354.

Maddison W, Maddison D (2011): Mesquite: a modular system for evolutionary analysis, version 2.75 .

Marino L (2004): Cetacean brain evolution: multiplication generates complexity. Int J Comp Psychol 17:1-16.

Martin RD (1981): Relative brain size and basal metabolic rate in terrestrial vertebrates. $\mathrm{Na}-$ ture 293:57-60.

-Martin RD, Genoud M, Hemelrijk CK (2005): Problems of allometric scaling analysis: examples from mammalian reproductive biology. J Exp Biol 208:1731-1747.

Martin J, Martin A (2007): Resource distribution influences mating system in the bobuck (Trichosurus cunninghami: Marsupialia). Oecologia 154:227-236.

McKenna A (2005): Husbandry and breeding of the striped possum Dactylopsila trivirgata at London ZSL. Int Zoo Yearb 39:169-176.

Meier PT (1983): Relative brain size within the North American Sciuridae. J Mammal 64: 642-647.

Olson VA, Liker A, Freckleton RP, Székely T (2008): Parental conflict in birds: comparative analyses of offspring development, ecology and mating opportunities. Proc Biol Sci 275: 301-307.

Pagel MD (1992): A method for the analysis of comparative data. J Theor Biol 156:431-442.

Pagel MD (1999): Inferring the historical patterns of biological evolution. Nature 401:877-884.

- Palombo MR, Kohler M, Moya Sola S, Giovinazzo C (2008): Brain versus body mass in endemic ruminant artiodactyls: a case studied of $\mathrm{Myo}$ tragus balearicus and smallest Candiacervus species from Mediterranean Islands. Quat Int 182:160-183. 
Paradis E, Claude J, Strimmer K (2004): APE: analyses of phylogenetics and evolution in $\mathrm{R}$ language. Bioinformatics 20:289-290.

Pinheiro J, Bates D, DebRoy S, Sarkar D; R Core Team (2014): nlme: linear and nonlinear mixed effects models, $\mathrm{R}$ package version 3.1117.

Pitnick S, Jones KE, Wilkinson GS (2006): Mating system and brain size in bats. Proc Biol Sci 273:719-724.

Purvis A (1995): A composite estimate of primate phylogeny. Phil Trans R Soc Lond B Biol Sci 348:405-421.

R Core Team (2014): R: a Language and Environment for Statistical Computing, v. 2.15.2. Vienna, R Foundation for Statistical Computing.

Reader SM, Laland KN (2002): Social intelligence, innovation, and enhanced brain size in primates. Proc Natl Acad Sci USA 99:4436-4441.

Rowe TB, Macrini TE, Luo ZX (2011): Fossil evidence on origin of the mammalian brain. Science 332:955-957.

Runcie MJ (2000): Biparental care and obligate monogamy in the rock-haunting possum, Petropseudes dahli, from tropical Australia. Anim Behav 59:1001-1008.

-Sakai ST, Arsznov BM, Lundrigan BL, Holekamp KE (2011): Brain size and social complexity: a computed tomography study in Hyaenidae. Brain Behav Evol 77:91-104.

-Sarko DK, Catania KC, Leitch DB, Kaas JH, Herculano-Houzel S (2009): Cellular scaling rules of insectivore brains. Front Neuranat 3:8.

Schillaci M (2006): Sexual selection and the evolution of brain size in primates. PLoS One 1:e62.

-Shultz S, Dunbar RIM (2006): Both social and ecological factors predict ungulate brain size. Proc Biol Sci 273:207-215.
Shultz S, Dunbar RIM (2007): The evolution of the social brain: anthropoid primates contrast with other vertebrates. Proc Biol Sci 274: 2429-2436.

Shultz S, Dunbar RIM (2010a): Social bonds in birds are associated with brain size and contingent on the correlated evolution of life-history and increased parental investment. Biol J Linn Soc Lond 100:111-123.

Shultz S, Dunbar R (2010b): Encephalization is not a universal macroevolutionary phenomenon in mammals but is associated with sociality. Proc Natl Acad Sci USA 107:2158221586.

Sibly RM, Brown JH (2007): Effects of body size and lifestyle on evolution of mammal life histories. Proc Natl Acad Sci USA 104:1770717712.

Smaers JB, Dechmann DKN, Goswami A, Soligo C, Safi K (2012): Comparative analyses of evolutionary rates reveal different pathways to encephalization in bats, carnivorans, and primates. Proc Natl Acad Sci USA 109:1800618011.

Sol D (2009): Revisiting the cognitive buffer hypothesis for the evolution of large brains. Biol Lett 5:130-133.

Sol D, Székely T, Liker A, Lefebvre L (2007): Bigbrained birds survive better in nature. Proc Biol Sci 274:763-769.

-Swanson EM, Holekamp KE, Lundrigan BL, Arsznov BM, Sakai ST (2012): Multiple determinants of whole and regional brain volume among terrestrial carnivorans. PLoS One 7:e38447.

-Temrin H, Tullberg BS (1995): A phylogenetic analysis of the evolution of avian mating systems in relation to altricial and precocial young. Behav Ecol 6:296-307.
Tyndale-Biscoe H (2005): Life of Marsupials. Collingwood, CSIRO.

- van Woerden JT, van Schaik Carel P, Isler K (2010): Effects of seasonality on brain size evolution: evidence from strepsirrhine primates. Am Nat 176:758-767.

van Woerden JT, Willems EP, van Schaik CP, Isler K (2012): Large brains buffer energetic effects of seasonal habitats in catarrhine primates. Evolution 66:191-199.

Walker R, Burger O, Wagner J, Von Rueden CR (2006): Evolution of brain size and juvenile periods in primates. J Hum Evol 51:480-489.

-Weisbecker V (2010): Why 'late equals large' does not work. Neuroscience 164:1648-1652.

Weisbecker V, Ashwell K, Fisher DO (2013): An improved body mass dataset for the study of marsupial brain size evolution. Brain Behav Evol 82:81-82.

Weisbecker V, Goswami A (2010): Brain size, life history, and metabolism at the marsupial/placental dichotomy. Proc Natl Acad Sci USA 107:16216-16221.

Weisbecker V, Goswami A (2011): Marsupials indeed confirm a general mammalian pattern: a reply to Isler. Bioessays 33:358-361.

-Weisbecker V, Goswami A (2014): Reassessing the relationship between brain size, life history, and metabolism at the marsupial/placental dichotomy. Zool Sci 31:608-612.

Weston EM, Lister AM (2009): Insular dwarfism in hippos and a model for brain size reduction in Homo floresiensis. Nature 459:85-88.

Winter J, Atherton R (1984): Social group size in north Queensland ringtail possums of the genera Pseudocheirus and Hemibelideus; in Smith A, Hume I (eds): Possums and Gliders. Chipping Norton, Beatty, pp 311-319. 